\title{
Information Management (IM) for Academic Staff Advancement Programme in Higher Institutions
}

\author{
Siti Emalia Merzuki (I), Hamrila A. Latif (2)
}

\begin{abstract}
The higher institutions basically adopted the concept of further education and purposefully organized research into programmes structured under the institutional academic staff advancement programme. The nature of the programme involves all kind of information, which needs to be turned into useful information before it can be transmitted or disseminated to accommodate the needs of stakeholders and to support the institutional integral functions through its collection, relevance, dissemination, and retrieval. The study reveals the needs for higher academic institutions to have in place a proper information system to preserve their corporate records and the involvement by the information professionals from all level of management and designated to have the knowledge and skills in Information Management (IM) that would consecutively improves their working processes as a whole. Therefore, this study explores the issues revolving within the management of staff academic advancement program in higher institutions and attempts to develop the understanding of how a systematic information management may serve to improve and simplify the tasks.
\end{abstract}

Keywords: information management; staff advancement; higher education; advancement program.

(I) msemalia@pak.unimas.my

(2)Correspondng 叉address: E-mail: e73928@ems.rmit.edu.au. Department of Business, Faculty of Economics \& Business, University Malaysia Sarawak, 94300 Sarawak, Malasia. 


\section{Introduction}

The higher institutions are unique in their existence, and require proper studies to be in place to develop understanding for an information strategy of the institutions. Being an information-intensive industry, not all of the data available to the institutions is in the right form, nor is available at just the right time (George \& King, 1991). As the consequence of growth in business complexity, has demanded for more and more information from the higher institutions.

More broadly, information in any of its many forms lies at the heart of the university's primary activities and posed the role that supports the higher institution's integral functions through its collection, relevance, dissemination, and retrieval (Davy, 1998). Nevertheless, the culture within the universities and their implementation of information strategies are described as "messy" and lacking in clarity or understanding (Neyland \& Surridge, 2002).

There is no clear strategy on how to initiate a system that would fit the information needs of the users. The higher institutions tend to stress too much on the technologies, internal institutional factors and processes (Allen \& Wilson, 1997). These problems tend to occur in most "old" universities for having strategies focussing too much on IT-oriented and procurement driven which have failed to meet the needs of users (Cullen, et al, 2003). Several authors have highlighted that the real power of information management comes from the integration of the various management functional systems into one overall information system (Knight \& Silk, 1990). Therefore, there is a need to place more attention on how people interact with information, the importance to understand the institution's information environment and the way people use information (Davenport, 1997).

Realizing the fact that the staffs of higher academic institutions are regarded as the key resources that contribute significant impact towards the establishment of these institutions as learning organizations, it is essential effort for the institutions to understand the operational environment that contributes towards the effective implementation of the academic staff advancement programmes. This involves internal environment consisting of data flows, information processes, physical processes and any related activities that support the daily operational business of the institution. Moreover, despite of the understanding towards its importance and the provisions of support for the purpose of academic advancement programmes, the higher institutions need to review and monitor the progress of this programme so that it will be inline with the mission of the developing human capital.
The nature of academic staff development programme involves all kinds of information derives from the policies, procedures, activities, people and technology. This information need to be altered, added to or simplify for record purposes so as to be turned into useful information before it can be transmitted or disseminated. This is in particular when involving a variety category of stakeholders with potentially different requests to the types of information, varying levels of details and complexity, and for differing reasons. The task of developing an information strategy and systems to support these needs is not a small challenge, particularly when it involves the same sets of data that is simultaneously used as the basis for informative and promotional messages (Burrows \& Harvey, 1992).

Undoubtedly, with no clear existence of a proper systematic information management, the task in acquiring, retrieving, and disseminating these information would be very tedious and difficult which can lead to additional work and time especially to identify the types of information required and to reorganize the information in packages that would fit the relative needs of the stakeholders. This is because most higher institutions have not yet put in place a general academic staff advancement programme and information strategy together that will provide proper guidelines on the broad goals, values and directions that would initiate and support the establishment of vision, policies and procedures to manage information. As such, these obstacles have lowered the administration and business capabilities in terms of flexibility and response speed to stakeholders' demand. It can result in reduced inventory and efficiencies, reliable delivery performance and competitive lead times.

\section{Literature Review}

In general, academic staff advancement programme is considered a unique and special scheme of which the individual may benefit in terms of the uninterrupted time during the pursuance of studies and researches, the eligibility to receive substantial funding as encouragement and recognition of achievement where appropriate, the opportunity to identify appropriate, realistic and achievable training or professional development needs and develop their full potential through the process of self-reflection, discussion and forward planning on their study leaves and sabbatical leaves. Two major terms that should be noted are "Study Leave" and "Sabbatical Leave". The first term refers to all activities involved for the purpose of academic advancement whereas the second one is more towards research purpose.

The University of Western Australia (2003) highlights the following important purposes for the granting of Study or Sabbatical Leave whether granted for full-time or part-time: 
i. It is an important strategy to augment the reputation of the higher institutions and that of the individual academic by supporting staff to pursue a range of endeavours seen as significant and pertinent to the University and to the individual;

ii. It confines the University's commitment to initiate, develop and retain high quality staff by providing release from teaching or related duties in pursuance for research and other scholarly work which requires uninterrupted periods of time; and

iii. It provides substantial support for staff looking at their teaching or skill developments within the identified field of expertise or to engage in a period of professional practice to keep abreast of professional developments.

The above emphasizes that the programme is one of the most significant elements in the career development of academic staff. As such, it is important to note that this allocated resources are precious to the selected academic staff who receive it and to the institutions that finance the studies and researches; requiring the needs to be managed in the most fair, efficient and effective way possible.

\section{Methodology and Limitation}

This project involved the use of qualitative approach of which one of the tools used for collecting the core data for this research was the semi-structured interview; a tool flexible enough in favouring adaptation of each context, organization and individual and also in pursuing unexpected paths and cues suggested and developed throughout the data gathering process. Observations and reviews of policies, minutes of meetings, reports, circulars, schemes, primary and secondary literatures, e-mails, oral histories and other related documents are utilized and contributed that contributes to consolidate impressions or confirm information based on documentary evidence or on the interviews. The information that emerged out of the data provided an empirical basis for the articulation of a grounded framework to the study.

This study described the attempt to introduce greater clarity and understanding of the ways in which information strategy may serve the higher institutions. The standing point would be the experiences of higher institutions, in the handling of the academic staff advancement programme and the associated information strategy stipulated and practised within the institutions. It should be borne in mind however, that the study focused exclusively on research towards the processes, information management issues and on the implementation of academic staff advancement programme, specifically the information confines within the concept of further education and research, and other related issues that are linked directly to the process. The study however did not detail out other development programmes or issues associated to human factors and information use by external stakeholders of which may require separate areas of research and further exploration.

\section{Results}

The academic staff advancement programme is one which, with the co-operation of all those involved in the process, offers great potential benefits for the individual member of staff, the department, the faculty and the institution as a whole.The data collected and information processed throughout the flow of management to the programme is essential to the institutions and regarded as the corporate information needs of which these needs for information must be satisfied in order for the institution to achieve its strategic aims. As such, the proposition should look into those parts of the value chain that were perceived by institutional members to be of critical significance. This would be inclusive of areas in which effort ought to be concentrated so that the information systems could be effective (Huotari \& Wilson 200I).

This has brought us to the heart of this study on the issues and challenges in handling the academic staff advancement programme in higher institutions and the necessity for a systematic flow of process which confines within the information management of framework (Refer Figure I: The Phases and Processes of Staff Advancement Programme in Higher Institutions). Generally, it is concerning with facilitating the career development, so that the academic staff would receive the advice and counselling needed to enable to do their jobs more effectively. Moreover, this is a two-way process, in which staff can discuss their current situation and its development over time, so that they can move towards their goals within the structure of the university and this requires for regular discussion to take place. 

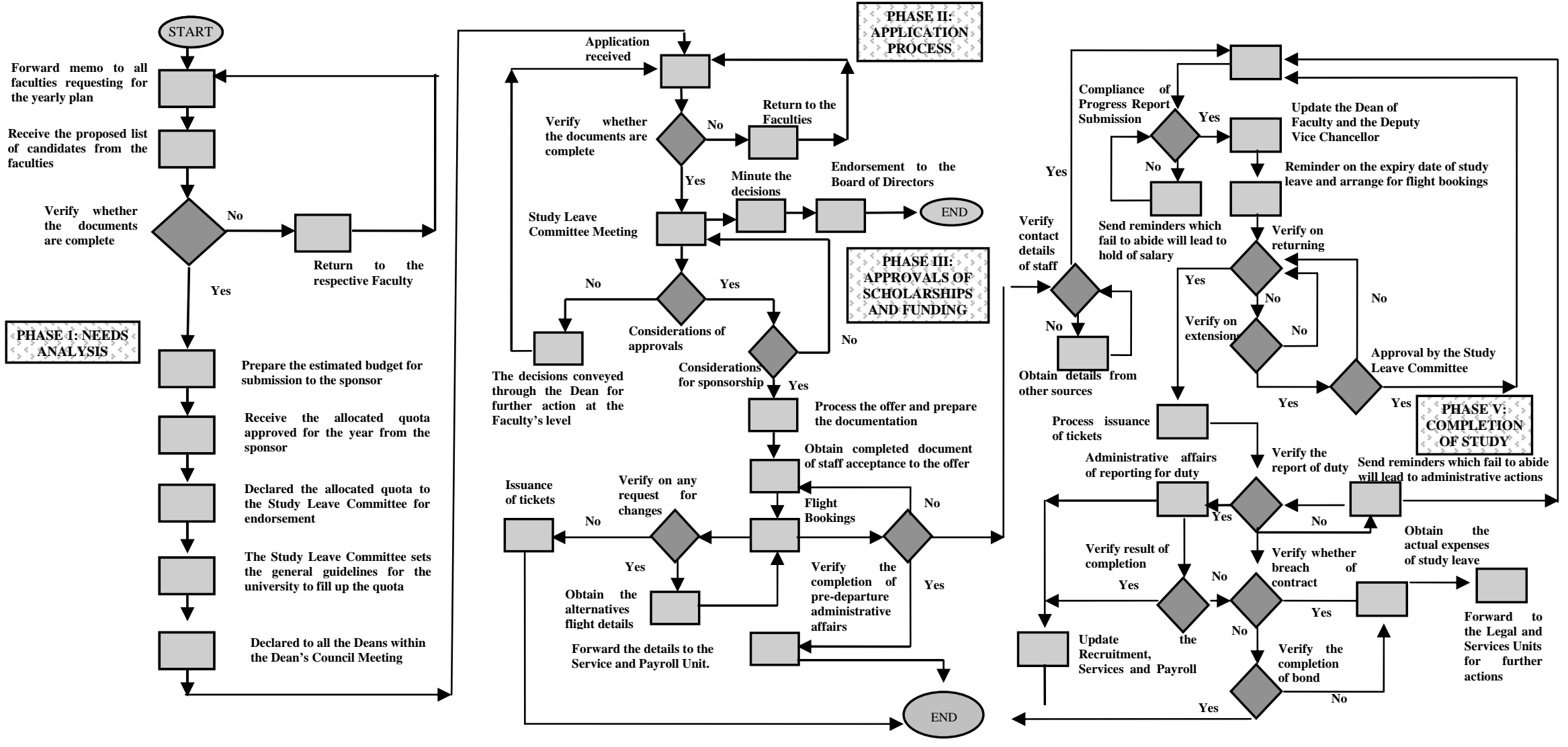

Figure 1: The Phases and Processes of Staff Advancement Programme based on Current Practice 


\section{A.The Needs for Effective Packaging of Information}

Based upon the procedures and guidelines elaborated in earlier section, it is crucial for the institutions to have in place proper means for the recording of documented policy and procedures that would facilitate actions undertaken in managing the programme. The conducting of the academic staff advancement programme and other related affairs requires each higher institution to implement many decisions of which involving the implicit making and keeping of records. The creation of these records whereby, is meant to communicate information and as to provide evidence of how the institutions acted to several matters. Undoubtedly, this demands for proper recording of information to ensure consistency, establish corporate memory, and provide an authoritative basis for establishing facts.

According to Seeman and O'Hara (2006), the institutions must first decide what information it needs about the customer and what it will do with it. Next, they need to determine how the information is gathered, where the data are stored, how it is used, and who uses it. However, not all documents created are records. The documents are only regarded as records once they are evidence of a business transaction undertaken and contribute to the administrative efficiency. The collected of information for each events that took place, decisions and discussions throughout the management of this programme needs to be recorded in the form of corporate memory to enable these facts to be retrieved whenever required. The information identified to be of value for record purposes involves:

i. Information gathered to support the affairs to which they are associated;

ii. Information that considered as crucial needs to protect the interests of the institutions, its clients, and others who might be affected by the decisions and actions based upon it;

iii. Information that has to be complied with legal obligations;

iv. Information that supports for accountability of requirements as listed within the scheme or policy; and

v. Information that of continuing value which requires for capturing and preserving of information to be in place.

(The University of Queensland, 2005)

The task of identifying the above groups of information is not an easy task. The gathering of data and supporting information of the programme occurs in each phase and involves continuous updating of information. The documents received come in different packages and require thorough checking for its completeness at every stage of collection, entry, storage and retrieval of which may require corrections and amendments to be recorded and documented. Few examples to these are:

i. E-mail: this is treated as the same status as paper records, hence should be captured and preserved electronically with copies might be placed in relevant files;

ii. Forms: paper-based records of which to be kept in files whereas selective data is recorded into the system;

iii. Authoritative documents: Letter of offer, copies of certificates, personal details, payroll and allowances details; and

iv. Authoritative instructions: Circulars, letter of instructions or guidelines from the Government, Treasury or the University.

Nevertheless, common errors tend to occur generally due to the assumption that the results from data entry procedures and the readily available written, published or stored information are accurate. As such, the failing to include or follow procedures in checking the accuracy of data coding, storage and retrieval due to the time or other constraints, leads to the failing of maintaining an audit trail for the data. This leads to timely checking to identify the main source to the information as not all of the data gathered is being captured into the records.

The obvious impact for not having an effective packaging of information is when it involves with various decision makings which demands for strong good records, specifically in the events where the academic staff applies for the extension period of their study leaves or appeal for change of programme or university. The manager of this programme would have to be able to group the information in accordance to the relevancy of issues raised. While reviewing the records of the staff involved, the manager must somehow locate sufficient relevant information to understand and solve the problem, or to supply the reliable summary of reports and relevant documents for further review in the management meetings. As the crosses of this large, diverse, disorganized collection of documents specifically for the particular problems, may lead to the situation where the manager has to make explicit choices about which items to ignore and which to examine more carefully. As such, the manager's choice creates a discrete subset of information and documents that are relevant to a given problem and likely to be of interest to other users of the collection who are concerned with the same problem.

In the occurrence of incomplete corporate memory and inefficient evidence to support decision-making, the institutions are 
forced to hold on any decisions if it is resulted with time-consuming for futile searches. The poor decision-making due to lack of accurate or complete records would reflect inefficiencies in administration and this is to the disadvantage not only to the institutions but to the staff, students, stakeholders and members of the community. The respective staff in particular, would have to deal with other related issues as means of survival within the country of studies as the decisions towards the extension period of study leave is linked to the extension of VISA, accommodation and other related affairs.

Another example is concerning the monitoring of welfare and release of allowance to the staff and family that would experience changes from time to time such as change of university, change of address, change of dependents details, change of procedures, allowances, claims of benefits and medical expenses. The needs for effective packaging of information will enable the managers to covert data to information that allows managers at al levels in all functions to make timely and effective decisions for the planning, directing, and controlling of activities for which they are responsible to.The programme demands for the institutions to have organized work process that would put further emphasize on the requirement of up-to-date, correct and fairly complete information to support the accountability requirements of the decision makers. It requires as well the capability of the personnel to identify the relevant information that would consecutively entail for the needs to cluster the information into different packages that would reduce issues of relevance, recall and precision while implementing the task of information storage and retrieval. These challenges however are not confining within the management of records in filing cabinets but also involving the electronic records, which is claimed to be the solutions to systematic information management. Above all, this is all involving a system that combines people, records management, work process and procedures that play a vital role of information management within the institution.

\section{B. Demands for Immediate Dissemination of Information}

Based upon Salter and Tapper (1994), the role of information has been perceived to have increased dramatically in addressing stakeholders' needs due to the changing nature of higher education and the pressure placed on institutions to satisfy numerous and various stakeholders. The significance highlighted by these authors seems to be of relevance even to this current date. This is supported by Marcella and Knox (2004) who elaborated on the role of information in contributing towards the success of the operational business activities that allows the institution to evolve and meet the challenges posed by the government, students and other stakeholders.
The Academic Staff Advancement Programme involves set of data, which is used repetitively based upon the requests by various stakeholders. Undoubtedly with no proper system in place for repetitive tasks, we pay repeatedly with our time for the same results. These internal and external stakeholders include students and their families, employers, teaching and administrative staff, government and funding bodies, creditors, quality auditors and assessors, professional and employer bodies.

In practice, there are several events or problems occur repetitively throughout the process within each phase. In general, the personnel assigned to handle the programme are the users of information who are considered as experts or team of experts, possessed of specialized knowledge, focussed on a specialized approach of "staff care task". The task, involving some aspect of staff care, is likely to be both generic and unique. It is assumed that most users in most circumstances need similar information to make a certain type of decision or to perform certain task. But in the academic staff advancement programme especially, every instance is expected to have unique elements, relating to the staff, the management, or to the faculty that variability cannot be completely care for in prior circumstances. As such, the personnel involved in handling this staff information is expected to be able to provide immediate response or advice based upon strong foundation of information gained through experiences as guidance to the respective staff, Dean of Faculty or even to the Top Management. Nevertheless, this implicit knowledge is usually not being documented or recorded as the managing of the process is basically based upon the understanding of the programme and its collaboration with other stipulated policies and governing conditions.

Nevertheless, the main challenge despite of the above fact is for having the institutions to identify the list of stakeholders involved within the system. The dissemination of information would caused unnecessary extra time and effort due to the repetitive tasks in structuring of reports and information required by users or stakeholders that may tend to vary even though the sources are of the same sets of data.

The main problem in terms of dissemination of information would be basically derives from the failure to define and understand the information needs of users and stakeholders (Basu et al., 2000). The dissemination of information tends to be in scattered form, which received from distributed sources. Therefore, the transferring of this information in small pieces, without setting the information in larger context due to the lack of understanding of the process itself, would indirect frightened the knowledge workers who are involved directly with the process of disseminating information (Brown \& Duguid, 2000). The massive production of everyday information tends to cause timely deliverable of services and basically will annoy 
users and makes it impossible to locate the relevant bits and pieces within the short notice of needs.

Kerr (1996) presented that the timely dissemination could be improved by focussing on the skills of:

i. Ability to find information that fulfil our needs;

ii. Ability to choose the most essential part of information; and

iii. Ability to analyze and synthesize collected information.

The knowledge that the individuals in the institutions have is pointed out as importance in dealing with the environmental circumstances effectively. It is about information, to be aware of the information channels, the attitudes, the use and the ability to forward information one gathers (Kay, 1993). It is noted that only by establishing the list of potential stakeholders and the relation to its sources that the higher institutions would improve their capabilities towards immediate dissemination of information.

\section{The Needs to Identify Pertinent Information Sources Useful for Data Management and Information Dissemination}

The purpose of information seeking is to look for information to meet a need. Judgements are made throughout the information seeking and the decision itself is a commitment to action following ongoing evaluation of pertinent information sources useful for data management and information dissemination. The uncertainty of information and time available for information seeking and retrieval is among the major constraints to decision makings in the managing of academic staff.

The increasing number of stakeholders would hold differing views about the purpose and nature of the tasks and adding to the complexity of what information was needed. As such, it is essential to identify what sort of information found to be useful as a precursor to putting together a structured information management of academic staff advancement programme.

\section{Lack of Comprehensive Governing Policies on Information}

Basically, there is still absentee or lacking of any established, integrated planning and budgeting process to acquire, manage, and use of the higher institutions' information systems. Specifically, the existing strategic plans that exist are not tied to each other, and the operational plans generally do not tie to the strategic plans. For instance, the existing plan of Information Technology Strategy within the institution might has limited practical application because it is not linked to other Human Resource information systems plans; does not address the systems, functions, and services within HIR nor is it based on current user needs; and it cannot be used as a budget tool to set priorities or allocate resources. Because of these planning deficiencies, in general, the Human Resources Information System's immediate and long term problems include:

i. The inability to manage, prioritize, and budget information resource activities;

ii. Potentially never achieving the vision of borderless;

iii. Inappropriate/misdirected support of multiple systems and the development of duplicate information systems;

iv. Funding shortages for critical information systems initiatives which ultimately may result in additional expenditures; and

v. Support of outdated systems and technology.

The study reveals that existing Human Resources Information System (despite of the different names used by different institutions) has not instituted the minimum information systems policies, standards, procedures, or guidelines to ensure efficient, effective, and consistent use of information resources. The lack of policies, standards, procedures, and guidelines has, in part, contributed to:

i. A failure to adhere to generally accepted system development practices which, in some cases, resulted in wasted time and money;

ii. The lack of a comprehensive data security program;

iii. Inadequate project management and change management practices;

iv. Support of outdated technologies and systems; and

v. Inadequate contingency/disaster recovery preparedness.

Moreover, the study also observed that Human Resources staffing levels in particularly for the academic staff advancement programme are, and have been in small number. Also, the Human Resources Management Department has only partially 
implemented the fundamental management practices of planning, organizing, directing, and controlling. Specifically, they did not have a comprehensive, updated information systems inventory or adequate operational plan; is currently operating in a reactive, crisis mode; lacked direction and leadership; and did not establish key control mechanisms. Thus, the integration has not been able to effectively accomplish its mission, which has negatively impacted the overall goals and objectives of the Human Resources Information Systems

Narrowing our scope towards the handling of academic staff advancement programme, the urgency to have a specific approach towards the management of data conversion into information (which is meaningful for the efficient flow of the process) has been rather neglected due to the understanding that the needs could be embedded into the Human Resource Management System. Even though this might be seen as an ideal approach but in practice, the management of data that contributes towards the success of this programme requires the higher institutions to have in place a more specific approach within the system.

The information space for this task includes the detail records of the staff which is considered as a large complex collection of information distributed across multiple, often geographically dispersed, information systems; some electronic and some paper-created by a diverse array of information professionals, for divergent purposes, over an extended period of time. Different classes of users however, may inhabit distinct territories within their space, rarely venturing into other regions (Ames, 1993). Importantly, the staff record itself is the only one of many sources of information (electronic or otherwise) that is likely to be employed in the management of academic staff advancement problems. The task of sorting through these sources in order to locate the required information can be formidable and time consuming.

The creation of a system within the institution has always been referred to the solving approach through computational software. Even though this might be true in the sense that the packaging of information would be made much easier with the aid of technological advancement, it might not be to the level of understanding and needs of the users. This is due to the fact that the management of this information is based upon the knowledge of the system analyst after several discussions and testing with the users. As electronic academic staff advancement programme information system expands and evolves, the diversity, size, and complexity are increasing dramatically while familiar cues that enable efficient navigation in printed media dispersed.This may result with an information management task that is even more formidable than before. Mainly this has been timely and rather vague in terms of its future record keeping and impact towards the end of these types of record's life cycle. Moreover, the electronic records are facing challenges due to the inability for us to anticipate future developments in technology. Therefore it is crucial for the managers to be able to accommodate such changes so that the used of software and hardware to process the records shall be catered in line with the current or changed formats to retain the survival of the records as archived items or to be migrated to other systems due to the changed of technology.

Bearmen (1993) suggested that there should be established standards for the intellectual control and documentation that should be above the standard norms of software dependent. Unlike in paper records the preservation is often considered only at the end of the life cycle whereas the electronic value, the decision to preserve the records or otherwise need to be done before the record is created. Yus of and Chell (2002) highlighted that the appraisal of records can be implemented at any stages, as the stages are actually overlapping and interwoven.

Without any clear guidelines and controls to this, the managers of this programme may basically confined their scope of understanding within the framework of data entries but not going beyond other issues such as accessibility, security, and any retention periods allocated for such purpose. As such, it is interesting to note at this point that, by definition, a system is any established set of procedures, policies, or guidelines directing an employee to the proper decision. If a practice, event or problem occurs repetitively, design a system to handle it; and when that system is established, make certain that everyone using it has a clear understanding (Frings, 2004).

\section{Recommendation}

The establishment of systematic information management is not solely referring to the creation of electronic records or purchase of software, but it is more of the approach to handle the programme by looking at methods for information support to its workflow process, techniques to improve the information quality aspects and provisions. The aims and objectives of the implementation whereby are depending upon the stakeholders' information needs so that the creation and grouping of information would ease the identification of the relevant data that are packaged into meaningful information and being released in accordance to the needs that emerged every phases and events. It is expected that this would contribute to the meeting and getting of critical information to those who need it in a sufficiently, timely fashion that it can contribute to the quality of the decisions they make (Scholtz, 2000). 
According to Neyland and Surridge (2002) indicated that:

"...it was not clear there was universal agreement that an Information Strategy was a good or useful idea and there was no clear agreement on what should be included in an Information Strategy or how an agreement should be reached."

In particular, because the academic staff advancement programme involves with vast amounts of information at the times and places where information intensive tasks are performed, the higher institutions have the potential to transform the work of this information management and decision making which are tightly integrated with the physical operations they perform. Undoubtedly, in order to achieve a truly beneficial transforma- tion of information requires a deep understanding of the work, the experts who perform it and the information tools and processes that they use.

The understanding of an Information System strategy is essential to clear the midst or ambiguity of the terms between Information Technology (IT), Information System (IS) and Information Management (IM). According to Wilson (I989), an information system strategy brings together the business aims of the organization, the understanding of information needed to support these aims and the implementation of computer systems to provide that information. Nevertheless, the broader concept given by Galliers (1993) on four distinct components that presents the IS strategy; is indeed interesting as below:

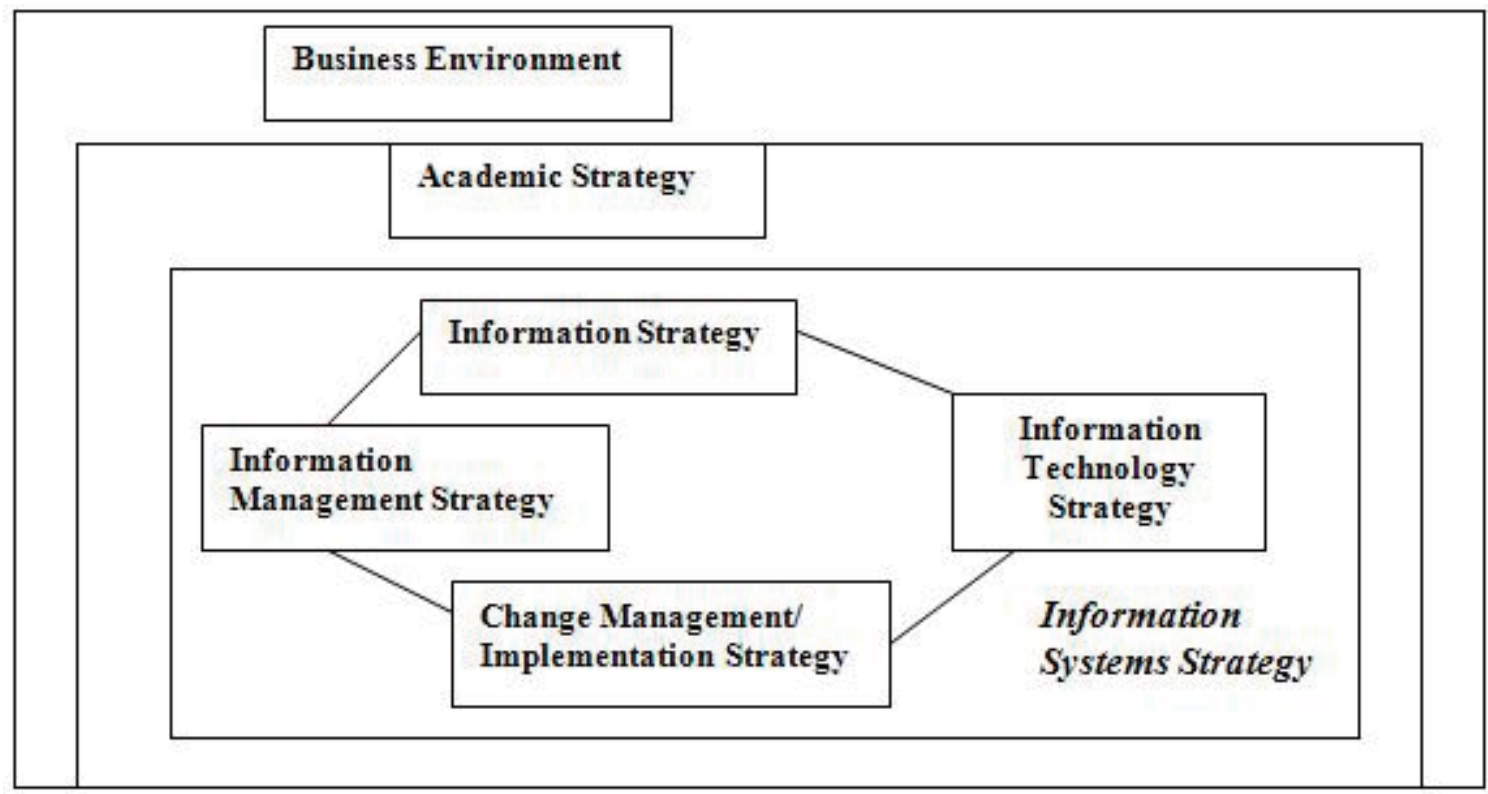

Note:

* Information Strategy acts as the key player between the Academic Strategy and the Information System Strategy that provides the answers to what and where the information is required to support the primary tasks, or key goals, of Academic Strategy.

* The Information Technology Strategy is given as of secondary importance, and is concerning of applications and platforms necessary to fulfil the requirements of the information strategy.

* The Information Management Strategy is concerning of the way information services are organized for the different facets of the institution and policy issues on information.

* The Change Management or Implementation Strategy identifies the organizational change needed for the Information System Strategy to be successful with specific plans and budgets drawn into the process.

Taking the approach of information management into the handling of academic staff advancement programme, the accessibility, reliability, consistency, and relevance of data underpinning information systems are crucial to its use and effectiveness in the setting of higher institutions.As such, the nature of the programme requires the focus of information strategy should be on the management of internal information. Developing a strategic information management systems, is important not only because of the importance of strategic decision making but to develop tools that provide good quality information that could be applied by the experts in updating their existing knowledge and fully-utilizing the information that is of relevant to the competitive environment. 
As noted by Goodman (1993), the critical success factor for correlation has been found between the management success and effective information needs assessment, gathering and use. Therefore, relevant and timely information would allow for accurate decisions made by the managers. The needs to use information is not only in making decision and making sense out of the changes and development that occur in the external environment, but it goes further beyond, where it is also being used to generate new knowledge to be applied to the designing new outputs and services that would enhance the existing benefits offered and improving the institutional processes. Therefore, in the changing environment, the strategy for the forming of systematic information management has been noted as importance as the higher institutions realized the needs to strategically plan for the gathering, storage and dissemination of their information resources.

\section{Conclusions}

It is time for the higher institutions to focus on a systematic handling to support academic staff advancement programme, which should be designed to take into account the entire record and information life cycle starting from the inputs until the archive stages. The important fact that should be emphasized is that without the proper information system, the higher institutions will be in an awkward position to seek and preserve their corporate information historical and valuable records concerning the programme as a move towards the improvement of the working processes itself.

Information Management should involves all level of management and designation. In short, the design of the organizations itself is in fact the very act of organizing, reflects the use of different methods of handling information and the use of teams, task forces or vertical information systems all reflect information processing needs within organizations. An organization skilled at creating, acquiring, organizing, and sharing knowledge is able to adapt its goals and behaviour to reflect new knowledge. Daft and Lengel (1984), and Choo (1996) refer to such an organization as an information-savvy "intelligent learning organization". Even though it is rather too early to be judgemental, it is not too ambitious to highlight in this study that the Academic Staff Advancement Programme has actually in place a system that has incorporated information management strategy and approach. The understanding on the needs for systematic and strategic information management is the key point for appreciating the nature of this programme that covers various disciplines of information which requires proper management to create the added value to all that are involved within the system.

\section{References}

ALLEN, D. \& Wilson, T.D. (1997), Information systems strategy formulation in higher education. In Understanding information policy: proceedings of a British Library funded Information Policy Unit Workshop, Cumberland Lodge, UK, 22-24 July, 1996. London: Bowker Saur

AMES, S.W. (1993). Multiple spoken and written channels of communication: An ethnography of a medical unit in a general hospital Dissertation. Buffalo, NY: State University of New York at Buffalo

BASU, J.S et al. (2000). Diffusion of executive information systems in organizations and the shift to the Web technologies. Industrial Management and Data Systems. I00(4), 27I-276.

BEARMAN D. (1993).Archival data management to achieve organizational accountability for electronic records. Archives as Manuscripts: The Journal of the Australian Society of Archivist. 2I (I). 14-28.

BROWN, J.S. \& Duguid, P. (2000). The Social Life of Information. Boston: Harvard Business Scholl Press.

BURROWS, A. \& Harvey, L. (1992). Defining quality in Higher Education: the stakeholder approach.

CHOO, C.W. (1996) The knowing organization: how organzations use information to construct meaning, create knowledge and make decision. International Journal of Information Management, 16(5), 23-40.

CULLEN, et al. (2003). Quality in higher education: from monitoring to management. Quality Assurance in Education, I ( I), 514.

DAFT, R. L. \& Lengel, R. H. (1984). Information richness: a new approach to managerial behavior and organization design. Research in Organzational Behavior, 6, 191-233.

DAVENPORT,T.H. (1997). Information ecology. Oxford: Oxford University Press.

DAVY, K. (1998). Information strategy and the modern utility: building competitive advantage. London: Financial Times Publishing.

FRINGS, C. (September, 2004). Relevance overwrites selective attention processes. In Congress of the German society for psychology, German: Gottingen. 
GALLIERS, R.D. (1993). Towards a flexible information architecture: integrating business strategies, information systems strategies and business process redesign. Journal of Information Systems. 3. 193-213.

GEORGE,J.F. \& King,J. L. (199I). Examining the Computing and Centralization Debate. Communications of the ACM. 34(7): 6372.

GOODMAN, S. K. (1993) Information needs for management decision making. Records management Quarterly October, 2I-22.

HUOTARI, M.L. \& Wilson, T.D. (200I). Determining organizational information needs: the Critical Success Factors approach. Information Research. 6(3). Paper 103. Available at http://informationR.net/ir/6-3/paper l03.html

KAY, J., (1993), Foundations of corporate success: how business strategies add value. Oxford: Oxford.

KNIGHT,A.V. \& Silk, D.J. ( 1990). Managing Information: Information Systems for Today's General Manager. London: McGraw-Hill.

MARCELLA, R. \& Knox, K. (2004). Systems for the management of information in a university context: an investigation of user need. Information Research. 9(2).

NEYLAND, D. \& Surridge, C. (2002, March). The contest for information strategy: utilising an alternative approach to produce "Good Management Practice". In The Strategy World Congress. UK: Oxford University.

SALTER, B. \& Tapper, T. (1994). The state and higher education. London:Woburn Press.

SEEMAN, E. D. \& O'Hara, M. (2006). Customer relationship management in higher education. Campus Wide Information Systems. 23(I), 24-34.

SCHOLTZ, J. (August, 2000). DARPA/ITO Information Management Program Background. Available: http://www.darpa.mil/ito/research/im/background.html)

The University of Western Australia. (2003). HR Policies and Procedures - Managing Staff at The University of Western Australia.Available at http://www.hr.uwa.edu.au/page/8222 .
WILSON, T.D. (1989). The implementation of information systems strategies in UK companies: aims and barriers to success. International Journal of Information Management. 9, 245-258. Available at http://informationr.net/tdw/publ/papers/ | 989|sstrat.html.

YUSOF Z. M. \& Chell R.W. (2002), Towards a theoretical construct for records management. Records Management Journal. I2(2) $55-64$ 